\title{
640 Gbaud NRZ-OOK data signal generation and 1.19 Tbit/s PDM-NRZ-OOK field trial
} transmission

Hu, Hao; Munster, P.; Palushani, Evarist; Galili, Michael; Dalgaard, Kjeld; Mulvad, Hans Christian Hansen; Jeppesen, Palle; Oxenløwe, Leif Katsuo

Published in:

OFC/NFOEC Postdeadline Papers

Publication date:

2012

Document Version

Publisher's PDF, also known as Version of record

Link back to DTU Orbit

Citation (APA):

Hu, H., Munster, P., Palushani, E., Galili, M., Dalgaard, K., Mulvad, H. C. H., Jeppesen, P., \& Oxenløwe, L. K. (2012). 640 Gbaud NRZ-OOK data signal generation and 1.19 Tbit/s PDM-NRZ-OOK field trial transmission. In OFC/NFOEC Postdeadline Papers (pp. PDP5C.7). Optical Society of America.

\section{General rights}

Copyright and moral rights for the publications made accessible in the public portal are retained by the authors and/or other copyright owners and it is a condition of accessing publications that users recognise and abide by the legal requirements associated with these rights.

- Users may download and print one copy of any publication from the public portal for the purpose of private study or research.

- You may not further distribute the material or use it for any profit-making activity or commercial gain

- You may freely distribute the URL identifying the publication in the public portal 


\title{
640 Gbaud NRZ-OOK data signal generation and 1.19 Tbit/s PDM-NRZ-OOK field trial transmission
}

\author{
H. Hu ${ }^{1}$, P. Münster ${ }^{2}$, E. Palushani ${ }^{1}$, M. Galilii ${ }^{1}$ K. Dalgaard ${ }^{1}$, H.C.H. Mulvad ${ }^{1}$, P. Jeppesen ${ }^{1}$ and \\ L. K. Oxenløwe \\ ${ }^{1}$ : DTU Fotonik, Technical University of Denmark, Building 343, DK-2800 Lyngby, Denmark \\ ${ }^{2}:$ Faculty of Electrical Engineering and Communication, Brno University of Technology, Purkynova 118, 61200 Brno, Czech Republic \\ huhao@fotonik.dtu.dk
}

\begin{abstract}
We demonstrate a field trial of a 640-Gbaud NRZ signal generated by RZ-to-NRZ conversion of a phase-coherent RZ-OTDM signal. This is employed in a 1.19-Tbit/s PDM-NRZOOK field transmission with $\mathrm{BER}<3.8 \times 10^{-3}$ for all 128 tributaries.

OCIS codes: (060.2330) Fiber optics communications; (070.7145) Ultrafast processing
\end{abstract}

\section{Introduction}

Optical networks may benefit from a combination of wavelength division multiplexing (WDM) and time division multiplexing (TDM) in terms of increasing transmission capacity and simplifying management. TDM can be realized electrically (ETDM) or optically (OTDM). Currently, the highest symbol rate and bit rate of ETDM are 100 Gbaud and $400 \mathrm{Gbit} / \mathrm{s}$, using modulation formats of NRZ and PDM-16-QAM [1-3]. The NRZ modulation format is considered the most straightforward implementation. However, it is difficult and power hungry to further increase the symbol rate of ETDM due to the bandwidth limitation of the driving RF amplifiers. On the other hand, OTDM has achieved a symbol rate of 1.28 Tbaud and a single-channel bit rate of $9.5 \mathrm{Tbit} / \mathrm{s}$ [4-6]. However, traditional OTDM with RZ format suffers from very broad spectra making transmission very challenging.

In this paper, we report the first demonstration of a field transmission of a 640 Gbaud NRZ data signal, derived from a phase-coherent OTDM RZ signal. The 640 Gbaud NRZ OOK data signal is polarization multiplexed to a line rate of $1.28 \mathrm{Tbit} / \mathrm{s}$, and transmitted through a $56 \mathrm{~km}$ field transmission link. The $640 \mathrm{Gbaud} \mathrm{NRZ} \mathrm{signal} \mathrm{is} \mathrm{tolerant} \mathrm{to}$ rectangular filtering with a bandwidth of $700 \mathrm{GHz}$ with negligible power penalty. All $128 \mathrm{TDM}$ tributaries (both TM and TE) are below the FEC limit after transmission, corresponding to $1.19 \mathrm{Tbit} / \mathrm{s}$ error-free field transmission.

\section{Experimental setup}

Fig. 1(a) shows the experimental setup for the field trial of the $1.19 \mathrm{Tbit} / \mathrm{s}$ NRZ OTDM signal. It mainly consists of a $640 \mathrm{Gbit} / \mathrm{s}$ RZ-OOK OTDM transmitter ( $\mathrm{L}$ band), a coherent OTDM generator, a polarization multiplexer, a field transmission link, a polarization demultiplexer and a $640 \mathrm{Gbit} / \mathrm{s}$ receiver. A $640 \mathrm{Gbit} / \mathrm{s}$ OTDM RZ signal at $1590 \mathrm{~nm}$ is generated by optical time division multiplexing a $10 \mathrm{GHz}$ short pulse, which has been on-off-keying (OOK) modulated at the $10 \mathrm{Gbit} / \mathrm{s}$ base rate with a PRBS $\left(2^{31}-1\right)$ signal [5]. The $640 \mathrm{Gbit} / \mathrm{s}$ data pulse has a FWHM of $600 \mathrm{fs}$. To generate a phase-coherent OTDM signal, the original OTDM signal is mapped onto a coherent CW light beam. A coherent signal is needed in order to convert it to NRZ. The coherent OTDM generator is basically a polarization-rotating Kerr switch [7] as shown in Fig. 1(b). The 640 Gbit/s data pulses and coherent CW light beam at $1545 \mathrm{~nm}$ are launched into a highly nonlinear fiber (HNLF). At the fiber output a polarizer is placed with its axis (vertical axis in Fig. 1(b)), orthogonal to the CW light. The polarization of the data is $45^{\circ}$ with respect to the polarizer. The $640 \mathrm{Gbit} / \mathrm{s}$ data pump switches the CW light by cross-phase modulation (XPM) induced polarization rotation in the HNLF, which generates a pulse-to-pulse phase-coherent OTDM signal. The HNLF of $128 \mathrm{~m}$ used in

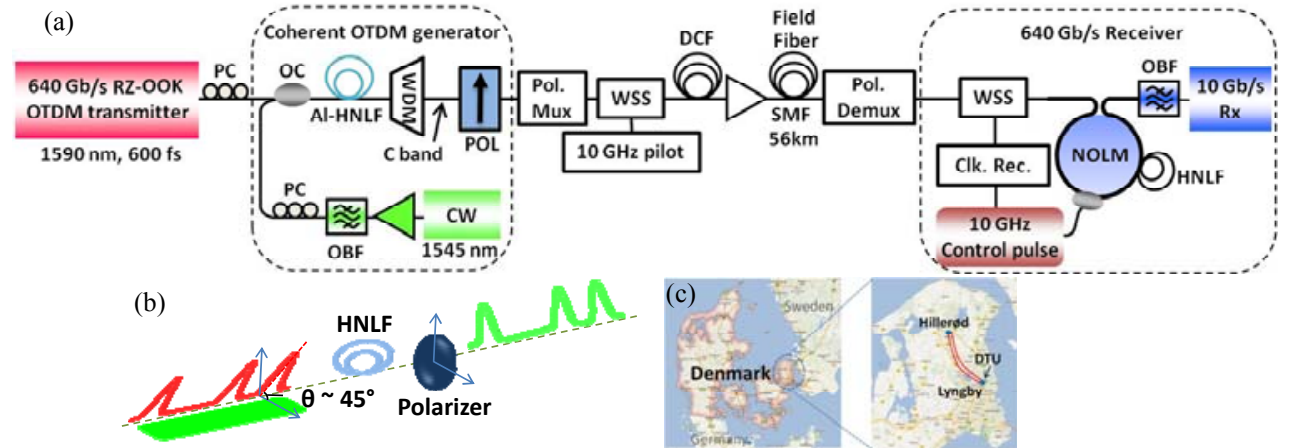

Fig. 1. (a) Experimental setup for the field transmission of a $1.28 \mathrm{Tbit} / \mathrm{s}$ Polmux-NRZ signal. PC: polarization controller, OC: optical coupler, HNLF: highly nonlinear fiber, WDM: wavelength splitter (C and L band), POL: polarizer, CW: continuous wave, OBF: optical bandpass filter, Pol. Mux: polarization multiplexer, WSS: wavelength selective switch, Pol. Demux: polarization demultiplexer, Clk. Rec.: clock recovery, NOLM: nonlinear loop mirror. (b) The principle of the Kerr switch based coherent OTDM generator. (c) Route of the field installed fiber. 

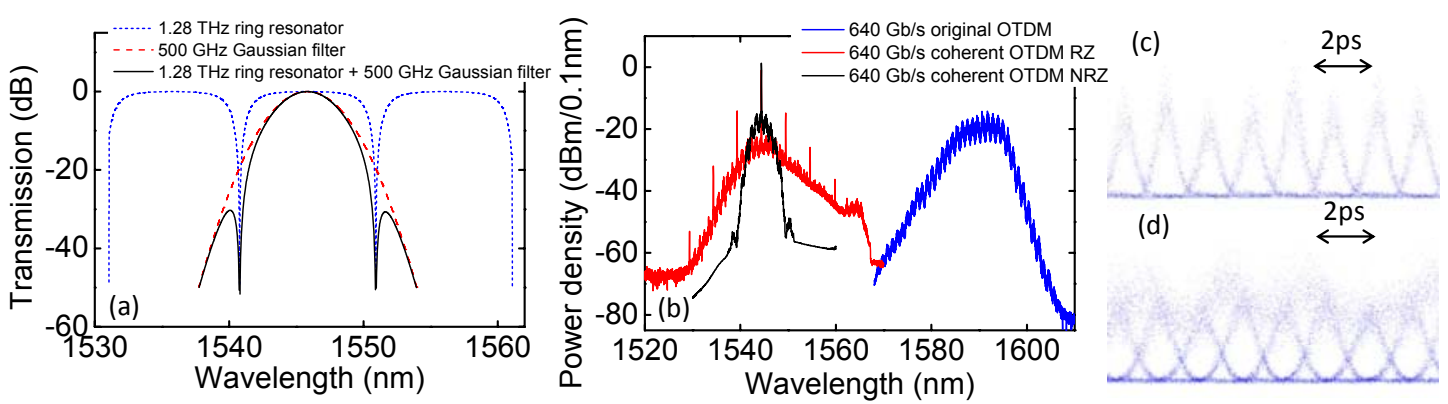

Fig. 2. (a) Filtering function of the WSS; (b) Spectra of original $640 \mathrm{Gbit} / \mathrm{s} \mathrm{L}$-band OTDM signal, generated $640 \mathrm{Gbit} / \mathrm{s}$ coherent OTDM RZ signal and NRZ signal; (c) and (d) optical sampling eye diagrams of the $640 \mathrm{Gbit} / \mathrm{s}$ coherent OTDM RZ signal and NRZ signal.

the experiment is alumino-silicate strained in order to increase the Stimulated Brillouin Scattering (SBS) threshold [8], and is kindly provided by OFS Fitel Denmark. The average power of the data and the CW light are $25 \mathrm{dBm}$ and $27 \mathrm{dBm}$, respectively. The zero-dispersion wavelength of the Al-HNLF is at $1560 \mathrm{~nm}$, minimizing the walk-off.

The $640 \mathrm{Gbit} / \mathrm{s}$ coherent OTDM signal is then polarization multiplexed by the polarization multiplexer, consisting of a polarization maintaining optical coupler, an optical delay line to provide 4800 symbol delay, and a polarization beam combiner to recombine the signal. Thus, a $1.28 \mathrm{Tbit} / \mathrm{s}$ line rate phase-coherent OTDM signal is generated, which corresponds to a data rate of $1.19 \mathrm{Tbit} / \mathrm{s}$, after subtracting the $7 \%$ FEC overhead.

A wavelength selective switch (WSS) is used to implement a filtering function by combining those of a 1.28 THz ring resonator and a $500 \mathrm{GHz}$ Gaussian filter, as shown in Fig. 2(a), in order to convert the RZ format into NRZ format. The spectra of the original $640 \mathrm{Gbit} / \mathrm{s}$ OTDM, the generated $640 \mathrm{Gbit} / \mathrm{s}$ phase-coherent RZ and the $640 \mathrm{Gbit} / \mathrm{s}$ NRZ signals are shown in Fig. 2(b). Optically sampled eye diagrams of the $640 \mathrm{Gbit} / \mathrm{s}$ coherent OTDM $\mathrm{RZ}$ and NRZ signals are shown in Fig.2(c-d). Finally, an in-band 10-GHz pilot tone at $1539.6 \mathrm{~nm}$ is inserted through the WSS for clock recovery (Fig. 3(a)).
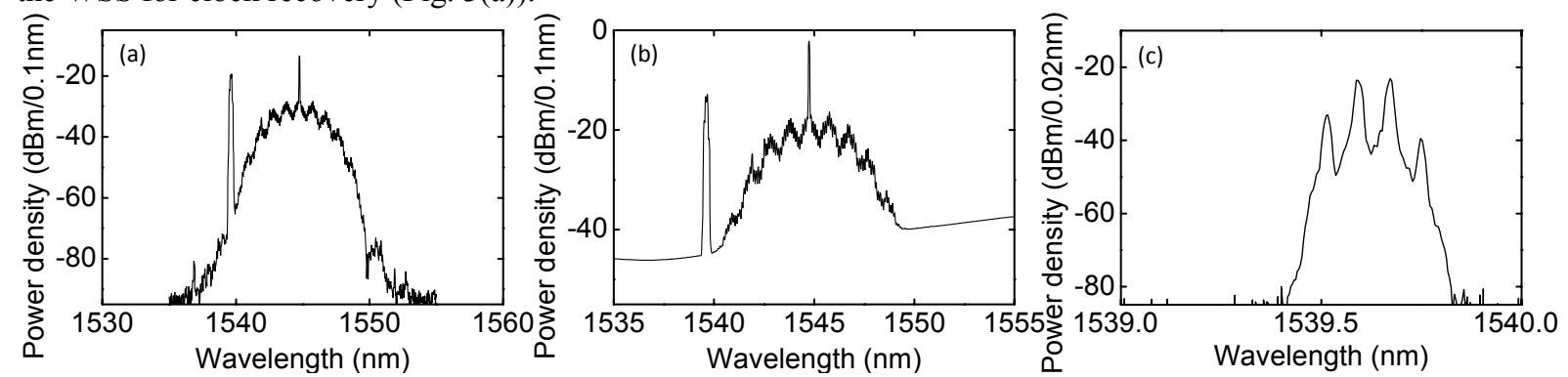

Fig. 3. Spectra of (a) $1.28 \mathrm{Tbit} / \mathrm{s}$ coherent OTDM signal with in-band $10 \mathrm{GHz}$ pilot tone at the output of the transmitter; (b) $1.28 \mathrm{Tbit} / \mathrm{s}$ coherent OTDM signal with in-band $10 \mathrm{GHz}$ pilot tone after the field transmission; (c) the extracted $10 \mathrm{GHz}$ pilot tone in the receiver.

The $1.28 \mathrm{Tbit} / \mathrm{s}$ signal is dispersion pre-compensated by a $7-\mathrm{km}$ DCF and then launched into a $56-\mathrm{km}$ field transmission link, which is a loop between the DTU lab in Lyngby and Hillerød in Denmark, Fig. 1(c). The launched power into the field transmission link is $11 \mathrm{dBm}$, with less than $1 \mathrm{~dB}$ nonlinearity penalty when increased to $18 \mathrm{dBm}$, which is a benefit of the lower peak power of NRZ compared to RZ. The mean differential group delay (DGD) of the field installed fiber is $0.2 \mathrm{ps}$ and has negligible impact on the NRZ transmission.

The spectrum of the $1.28 \mathrm{Tbit} / \mathrm{s}$ pol-MUX NRZ signal with the in-band $10 \mathrm{GHz}$ pilot tone after the field transmission (Fig. 3(b)) reveals an OSNR of $\sim 41 \mathrm{~dB}$. The pol-MUX NRZ signal is then polarization demultiplexed by a polarization beam splitter (PBS) and subsequently received by a $640 \mathrm{Gbit} / \mathrm{s}$ receiver which consists of a WSS, a clock recovery (Clk. Rec.) unit, a nonlinear optical loop mirror (NOLM) based TDM demultiplexer, a $0.9 \mathrm{~nm}$ filter and a $10 \mathrm{Gbit} / \mathrm{s}$ pre-amplified receiver. The WSS is used to extract the $10 \mathrm{GHz}$ pilot tone (Fig. 3(c)) and act as a rectangular filter with a bandwidth of $\sim 800 \mathrm{GHz}$ (tuneable) to emulate strict filtering as in a WDM system. The extracted $10 \mathrm{GHz}$ clock is recovered by a phase-locked loop and then used to synchronize a mode-locked laser to generate $10 \mathrm{GHz}$ control pulses. The NOLM is used to demultiplex the $640 \mathrm{Gbit} / \mathrm{s}$ data signal to the $10 \mathrm{Gbit} / \mathrm{s}$ data tributaries.

\section{Experimental results}

The RZ-NRZ conversion and field transmission are successful. Fig. 4 shows BER-based characterization results B2B, and Fig. 5 after the field transmission. BER vs received power is plotted for a $10 \mathrm{Gbit} / \mathrm{s}$ channel demultiplexed from the $640 \mathrm{Gbit} / \mathrm{s}$ signals. In all cases, BER values below the FEC limit are obtained. The BER performance of the optimized $640 \mathrm{Gbit} / \mathrm{s}$ NRZ signal is similar to that of the $640 \mathrm{Gbit} / \mathrm{s}$ phase coheretn RZ signal. Fig. 4(a) shows 
the dispersion tolerance for the $640 \mathrm{Gbit} / \mathrm{s}$ NRZ and RZ data signals. As expected, the narrower spectrum of the NRZ data leaves it more tolerant to the added $\beta_{2}$ dispersion than the RZ. For uncompensated dispersion of 0.2 $\mathrm{ps} / \mathrm{nm}$, the $640 \mathrm{Gbit} / \mathrm{s} \mathrm{RZ}$ signal has an error floor at a BER of $10^{-3}$, whereas the $640 \mathrm{Gbit} / \mathrm{s} \mathrm{NRZ} \mathrm{signal} \mathrm{just} \mathrm{has} \mathrm{a}$ power penalty of $1.2 \mathrm{~dB}$ without an error floor. The error floor only appears for the $640 \mathrm{Gbit} / \mathrm{s} \mathrm{NRZ}$ signal when the uncompensated dispersion is increased to $0.5 \mathrm{ps} / \mathrm{nm}$. The $640 \mathrm{Gbit} / \mathrm{s} \mathrm{NRZ} \mathrm{signal} \mathrm{is} \mathrm{also} \mathrm{investigated} \mathrm{for} \mathrm{tolerance} \mathrm{to}$ the bandwidth of a rectangular filter, as shown in Fig. 4(b) and (c). When the filter bandwidth is larger than $700 \mathrm{GHz}$, the power penalty caused by the filtering effect is $<1 \mathrm{~dB}$; however the power penalty increases dramatically when the filter bandwidth is smaller than $600 \mathrm{GHz}$.
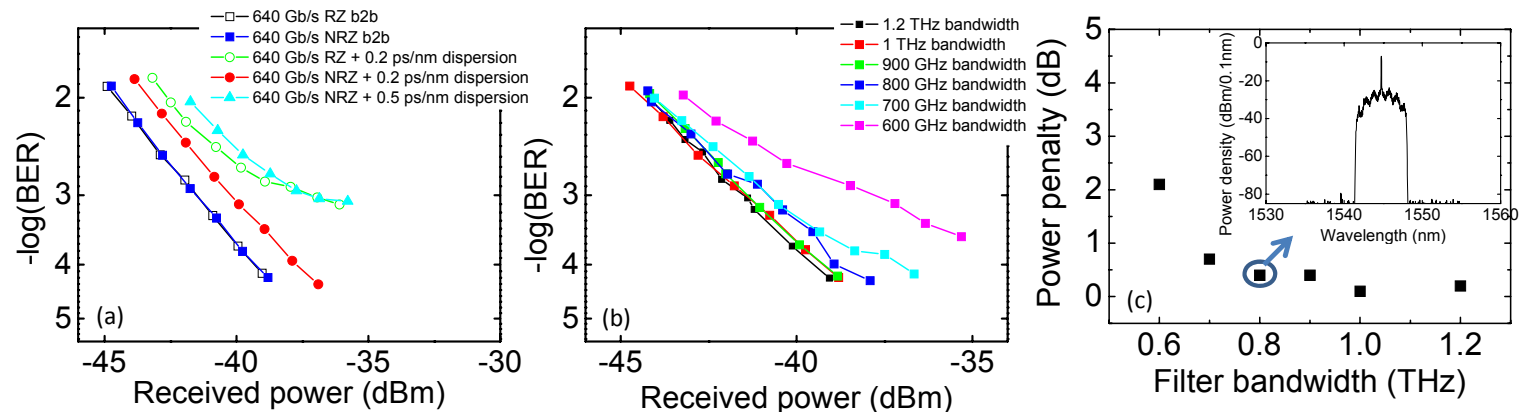

Fig. 4. B2B characterization. (a) Dispersion tolerance of $640 \mathrm{Gbit} / \mathrm{s} \mathrm{RZ}$ and NRZ with added uncompensated dispersion. (b) Filtering bandwidth tolerance of $640 \mathrm{Gbit} / \mathrm{s} \mathrm{NRZ} \mathrm{with} \mathrm{rectangular} \mathrm{filter} \mathrm{function.} \mathrm{(c)} 640 \mathrm{Gbit} / \mathrm{s} \mathrm{NRZ}$ power penalty at BER=3.8 $\times 10^{-3}$ for rectangular filtering with different bandwidths vs. optimum RZ case. Inset: spectrum of the $640 \mathrm{Gbit} / \mathrm{s} \mathrm{NRZ}$ after the rectangular filtering with a bandwidth of $800 \mathrm{GHz}$.

Fig. 5(a) shows an open optical sampling eye diagram of the $640 \mathrm{Gbit} / \mathrm{s}$ NRZ signal after the field transmission. The BER performances of the $640 \mathrm{Gbit} / \mathrm{s}$ NRZ and the $1.28 \mathrm{Tbit} / \mathrm{s}$ pol-MUX NRZ signal after the field transmission are shown in Fig. 5(b). Compared to the b2b case, the power penalty of the $640 \mathrm{Gbit} / \mathrm{s} \mathrm{NRZ}$ signal after the transmission is $<1 \mathrm{~dB}$ and the power penalty of the $1.28 \mathrm{Tbit} / \mathrm{s}$ pol-MUX NRZ signal after the transmission is $\sim 1 \mathrm{~dB}$ for both TM and TE mode, mainly due to a limited polarization extinction ratio of the PBS in front of the receiver. The BER of all the 128 tributaries (both TM and TE) are measured with a received power of $-37 \mathrm{dBm}(\mathrm{Fig}$. 5(c)). All the tributaries of the transmitted 1.28 Tbit/s signal show a BER below $2 \times 10^{-3}$, well below the FEC limit of 3.8 $\times 10^{-3}$. This corresponds to a post-FEC error-free performance $\left(\mathrm{BER}<10^{-12}\right)$ at a net data rate of $1.19 \mathrm{Tbit} / \mathrm{s}$.

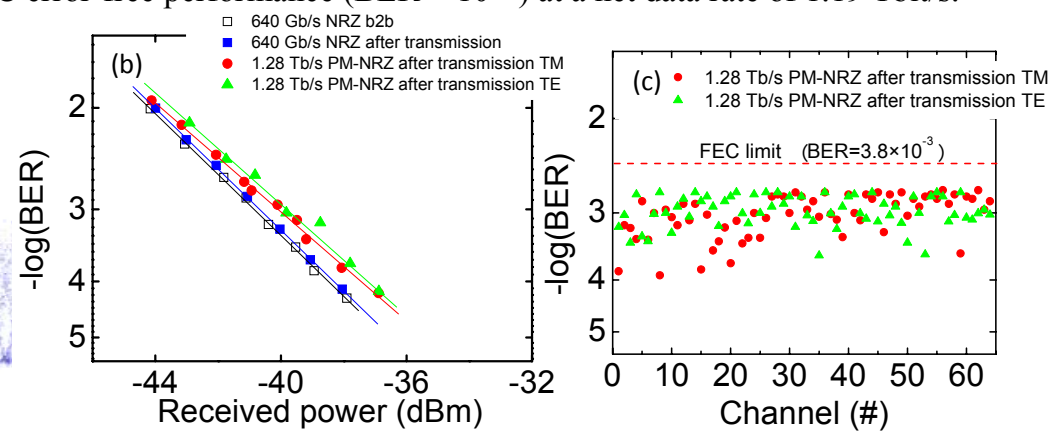

Fig. 5. Field transmission. (a) Optical sampling eye diagram of the $640 \mathrm{Gbit} / \mathrm{s}$ NRZ signal after the field transmission. (b) BER measurements for $640 \mathrm{Gbit} / \mathrm{s}$ NRZ back-to-back, $640 \mathrm{Gbit} / \mathrm{s}$ NRZ after field transmission, and for $1.28 \mathrm{Tbit} / \mathrm{s}$ pol-MUX NRZ after field transmission (TM and TE). (c) BER measurements for all the 128 tributaries (TM and TE) at a receiver power of $-37 \mathrm{dBm}$.

\section{Conclusion}

We have demonstrated the generation of a 640 Gbaud NRZ signal and a field trial of a 1.19 Tbit/s PDM-NRZ-OOK signal over a $56 \mathrm{~km}$ installed transmission link. All 128 tributaries show a BER below the FEC limit of $3.8 \times 10^{-3}$ after the field transmission. The bandwidth of the generated 640 Gbaud NRZ signal can be restricted to $700 \mathrm{GHz}$ with negligible power penalty. Furthermore, the phase coherent OTDM NRZ signal with narrower spectrum has better tolerance to dispersion compared to a traditional OTDM RZ signal.

\section{Acknowledgements}

We would like to acknowledge GlobalConnect A/S (Denmark) and UNI-C for supporting the field transmission link and OFS Fitel Denmark for providing the Al-HNLF.

\section{References}

[1] G. Raybon et al., OFC 2006, PDP 32.

[2] R. H. Derksen et al., OFC 2006, PDP 37.

[3] P. J. Winzer et al., ECOC 2010, PD 2.2.

[4] H. C. Hansen Mulvad et al., Opt. Express, 18, pp. 1438, 2010.

[5] P. Guan et al., Opt.Express 19, pp. B567-B573, 2011.

[6] T. Richter et al., OFC 2011, PDPA9.

[7] Y. Ding et al., Opt. Express, 19, pp. 6471, 2011.

[8] L. Gruner-Nielsen et al., ECOC 2010, Tu.4.D.3. 